\title{
RISK MANAGEMENT STRATEGIES ON SMALL-SCALE COMMERCIAL FARMS IN THREE ZOBATAT OF ERITREA
}

\author{
M A Mohammed, G F Ortmann and S R D Ferrer ${ }^{1}$
}

School of Agricultural Sciences and Agribusiness, University of KwaZulu-Natal, Pietermaritzburg

\begin{abstract}
In this study the perceptions of small-scale commercial farmers in Eritrea of the importance of various risk responses are ascertained and analysed to gain insight into their risk-management strategies. Data were elicited through a survey of 186 small-scale commercial farmers conducted in three zobatat (regions) of Eritrea. Factor Analysis is used to investigate heterogeneity in sample farmers' responses. Results indicate that relatively more important risk responses include the use of internal and external sources of information, on-farm and off-farm diversification, choice of production system and product marketing arrangements. Farmers' perceptions of risk responses vary according to farm type, geographical location, farm and farmer characteristics, as well as the existence of enterprise specific risk responses (e.g. livestock insurance) and differences in the marketing regulations of various agricultural products.
\end{abstract}

JEL Q12, 13

\section{1 \\ Introduction}

Risk refers to potential adversity due to unanticipated or random variation (Barry et al., 2000: 661), and may be described using the heuristics of the probability distribution of an outcome. Decision-making under risk, therefore, refers to a choice between alternatives, each associated with probability distributions; and risk management is the systematic application of management policies, procedures and practices to the tasks of identifying, analysing, assessing, treating and monitoring risk (Hardaker et al., 1997: 12). While it is impossible to eliminate risk, certain strategies can be employed to reduce or counter the adverse effects of imperfect knowledge (Held, 1990: 54). Commercial agriculture in Eritrea is characterised by high levels of social, political and environmental risks (Bekuretsion, 2002), hence risk management is an essential component of farm management in Eritrea. Opportunities for risk management in Eritrea, however, are undeveloped relative to those available in South Africa, the United States
(US) and the European Union. For example, agricultural insurance and futures markets are poorly developed or absent in Eritrea and Eritrean farmers have relatively poor access to credit, which limits their use of risk responses such as purchasing crop insurance, hedging and maintaining credit reserves.

Mohammed (2004) identified the major sources of risk facing farm businesses in Eritrea, as perceived by a sample of 186 smallscale commercial farmers in Eritrea, and also analysed their risk-management responses. This paper presents the important risk responses by the respondents and investigates how their perceptions of various production, marketing and financial risk responses vary geographically, across farm types, and according to farmer and farm business characteristics. Farmers' risk management strategies are expected to reflect their perceptions of risk responses. Results are used to identify possible shortcomings in farmers' risk-management strategies, and to consider implications for policy and extension towards ameliorating these shortcomings. Government interventions that reduce risks 
faced by farm businesses and enable improved risk management by farmers are expected to promote growth of the Eritrean rural economy.

The research approach adopted in this study is primarily based on that used in various studies of large-scale commercial agriculture in South Africa (e.g. Swanepoel and Ortmann 1993, Bullock et al. (1994), and Woodburn et al, 1995) and in the United States (e.g. Ortmann et al, 1992). As far as the authors are aware, no similar studies have been conducted in Eritrea or for small-scale commercial agriculture elsewhere in Africa.

\section{2}

\section{Background to risk management}

Risk-management strategies are developed to provide some shield in situations in which the consequences of a decision are not known at the time the decision is made, without excessively sacrificing gains. They typically comprise a bundle of risk-management responses, which include options for reducing risks, transferring risks and increasing risk-bearing capacity. The range of suitable risk responses may vary between farms and over time due to factors such as differences in characteristics of farms (e.g. farm type, size and proximity to markets), farmers (e.g. education, risk preference and capacity to bear risks), and institutional arrangements (e.g. whether or not efficient markets exist for agricultural insurance markets or futures markets) (Barry et al., 2000: 220). Conventionally, actions to reduce risk and to increase the business' risk- bearing capacity tend to be categorised as production, marketing, or financial risk responses, according to the type of risk that is addressed (Boehlje \& Trede, 1977; Sonka \& Patrick, 1984; Eidman, 1990; Barry et al., 2000: 220).

Evidence suggests that farmers behave in risk-averse ways (Young, 1979; Hazell, 1982). Pratt (1964) and Arrow (1974) independently developed equivalent measures of risk preferences that allow for comparison of interpersonal risk preferences. Moscardi and de Janvry (1977) and Binswanger (1980), among others, developed experimental approaches to elicit risk preferences of individuals. Moscardi and de Janvry (1977) found that youth, higher levels of education, greater total income and larger farm size to be associated with less risk aversion among peasant farmers. Patrick et al. (1993) found that education and percentage of land owned were, respectively, positively and negatively correlated to large-scale US Cornbelt farmers' willingness to take risks. To the authors' knowledge, no published research has reported on risk preferences and factors affecting risk preferences of Eritrean farmers.

Production responses by farmers generally act to reduce risk by reducing the variability in production. Farm enterprise diversification, for example, is a strategy long used by farmers to reduce price- or weather-induced production variability. Producers can diversify by engaging in many different activities in one time period, engaging in the same activity in many different physical environments or locations, or engaging in the same activity over many successive periods of time (Fleisher, 1990). Diversification is likely to be successful when returns from enterprises are negatively or weakly correlated, thus profits from one or more enterprises may offset any losses incurred in another enterprise (Debertin, 1986). Selection of technical practices, such as investment in excess machinery capacity, the use of insecticides in crop production, planting several varieties of seed, substituting capital inputs for labour and hiring labour for labourintensive works are other production-risk responses used by farmers to reduce the effect of risk (Sonka \& Patrick, 1984). Woodburn et al. (1995) found that keeping production records, making timely use of machinery and choice of production system were the most important production-risk responses by a sample of commercial farmers in KwaZuluNatal. Low-cost production, type of production system and keeping physical records featured strongly among extensive livestock farmers in the Bushveld region of South Africa (Swanepoel \& Ortmann, 1993). Commercial vegetable farmers in KwaZulu-Natal considered irrigation, timely access to machinery and being a low-cost producer as important production-risk responses (Bullock et al., 1994). Among a sample of US 
Cornbelt farmers, having "timely" machinery, being a low-cost producer and diversification of farming enterprises were the most important responses to production-risk (Ortmann et al., 1992).

Marketing responses may also reduce risk by narrowing the range of possible outcomes, or may involve transferring price risks to other individuals or institutions. Marketing options may be divided into indirect marketing to consumers and direct selling to consumers. Indirect marketing as a risk-management tool relies on formal contracts. Farmers transfer price or market risk to either wholesalers, for example, with the only concern of meeting the contract commitment due to yield variability. Direct marketing (vertical integration) involves sorting, assembling and packaging fresh products for retail sales. "The incentive for vertical integration can arise from producers or from buyers further down the marketing (supply) chain who realise an opportunity to enhance their potential profits or reduce their risk" (Harwood et al., 1999: 19). Woodburn et al. (1995) reported that the most important responses to marketing risk by a sample of commercial farmers in KwaZulu-Natal were selling on the free market, using market information and direct marketing to consumers. Bullock et al. (1994) found similar responses among a sample of commercial vegetable farmers in KwaZulu-Natal. For US Cornbelt farmers, forward contracting the selling price of crops, participation in government farm programmes and hedging the selling price of crops were considered important responses to marketing risk (Ortmann et al., 1992).

In contrast, financial responses generally emphasise the firm's capacity to bear risk and do not reduce the probability of an unfavourable event. Most financial risk responses involve the management of business leverage and liquidity. For example, off-farm investment illustrates the building of risk-bearing capacity (Harwood et al., 1999), whereas formal insurance may build liquidity and at the same time transfer risk acceptance outside the business (Barry et al., 2000: 240). Woodburn et al. (1995) and Bullock et al. (1994) found that keeping financial records, debt management, maintaining financial/ credit reserves and asset insurance were the most important financial risk responses by commercial farmers in KwaZulu-Natal. US Cornbelt farmers ranked liability insurance, maintaining financial/credit reserves and debt/ leverage management as important responses to financial risk (Ortmann et al., 1992).

Fleisher (1990: 73) maintains that a fourth category of risk responses is the use of internal and external information sources to reduce uncertainty in making production, marketing and financial decisions. Information, compared to other farm inputs and management tools, is in many respects unique and provides the basis for all aspects of farm management, including risk management.

3

\section{Study regions, sample and characteristics of respondents}

Eritrea is a country of north-eastern Africa bordered on the east by the Red Sea, in the south by Djibouti and Ethiopia, and in the north and west by Sudan. It is located between latitudes $12^{\circ} 42^{\prime} \mathrm{N}$ to $18^{\circ} 2^{\prime} \mathrm{N}$ and longitudes $36^{\circ}$ $30^{\prime} \mathrm{E}$ to $43^{\circ} 20^{\prime} \mathrm{E}$. The total area of the country is 121,320 square kilometres (CIA, 2005). Administratively, Eritrea is divided into six regions referred to as zobatat (singular - zoba) (Ghebreyohanes, 2000). The population is estimated at about 4.45 million with a 2.57 per cent growth rate per year. About 45 per cent of the population is between the ages of $0-14,52$ per cent between the ages of $15-64$, and 3.3 per cent above the age of 65 . The economy is largely based on subsistence agriculture, with 80 per cent of the population involved in farming and herding. In 2003 agriculture accounted for an estimated 12.4 per cent of the country's Gross Domestic Product (GDP) (CIA, 2005).

Data for this study were collected from three zobatat of Eritrea, namely Ma'akel, Debub and Gash-Barka, between November 2002 and February 2003. Dairy and poultry are the predominant commercial agricultural enterprises in Ma'akel; however, some farmers produce vegetables for sale in Asmara, the capital city. The primary commercial agricultural 
enterprises in Debub are dairy (mostly diversified with vegetable farming), poultry, irrigated horticultural farming (oranges, lemons, apricots, guavas and papaya), and field crop production (barley, maize, wheat and taff). In Gash-Barka, the largest zoba, field cropping (millet, sorghum and sesame) and horticultural production (banana, papaya, citrus) are the predominant commercial enterprises. Vegetables and milk are produced primarily for informal local markets as relatively poor infrastructure and the hot climate largely precludes farmers marketing perishable produce in relatively distant formal markets. Poultry farming is in its infancy in this zoba.

A sample of farmers to be interviewed was randomly selected from a list of commercial farmers provided by the Ministry of Agriculture. A summary of the sample proportions is presented in Appendix A. The number of sample farmers involved in four enterprises and three zobatat are roughly proportional to the number of farmers in the population. The sample of 186 farmers, of whom 42 are from Ma'akel, and 72 each from Debub and GashBarka, was interviewed. Of the sample, 40 are poultry farmers, 31 horticultural, 74 dairy, and 41 are crop farmers (Note: these farmers were classified according to major enterprise although diversification does occur on many farms). On average, horticulture and field crop farms are large in terms of area (mean areas of 102 and 87.9 hectares, respectively) in comparison to dairy and poultry farms (mean areas of 2.1 and 1.5 hectares, respectively). Over 80 per cent of poultry and field crop farms had a mean annual turnover of less than $300000 \mathrm{Nakfa}$ (US\$1 = 14.5 Nakfa at the time of the study), whereas over 80 per cent of horticulture and dairy farms had a mean annual turnover in excess of 300 000 Nakfa.

Over 74 per cent of farmers surveyed, including all field crop farmers, were individual owners of their businesses and 22 per cent were in a partnership with other family members. In general, the level of education of survey respondents was relatively low. Only 3 per cent of respondents held tertiary education qualifications and a further 7.5 per cent had completed college or technical school. More than 57 per cent of respondents had not attended secondary school. In general, horticulture and poultry farmers had more formal education than dairy and field crop farmers.

\section{4 \\ Methodology and managerial responses to risk}

The set of managerial responses included in this study are those considered most relevant to Eritrean agriculture, and were determined using expert advice and a pilot survey of ten Eritrean farmers. Previous studies, such as Ortmann et al. (1992) and Woodburn et al. (1995), included different sets of risk- management responses in their studies, reflecting that farmers' riskmanagement opportunities vary across countries, over time, and between small- and large-scale farm businesses. Survey respondents were requested to rank the importance of each risk response using a Likert-type scale with a range from one (not important) to five (very important).

\subsection{Mean ratings of managerial responses to risk}

The production, marketing and financial risk management responses considered in this study, together with survey respondents' mean rankings of the importance, are presented in Table 1 . The mean ratings are provided for the whole sample, for the three zobatat and for four enterprise types. 


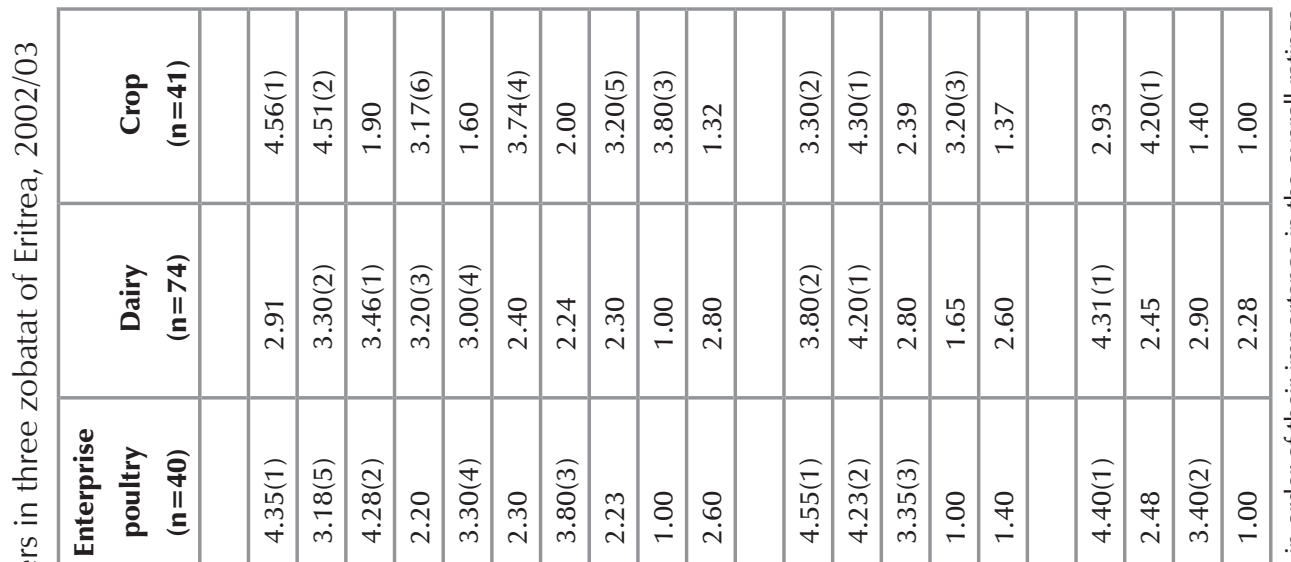

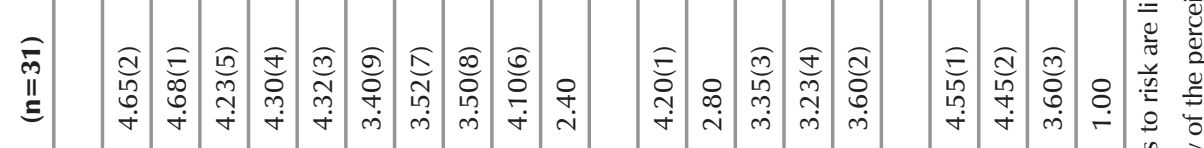
원

. 를

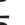

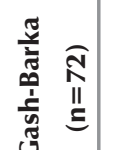

$\frac{0}{2}$

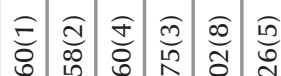

อิ

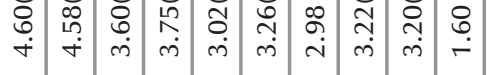

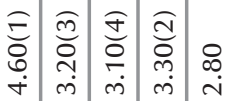

○

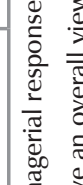

造

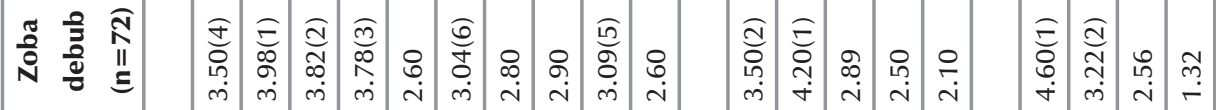

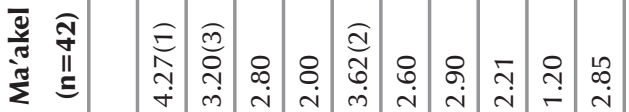

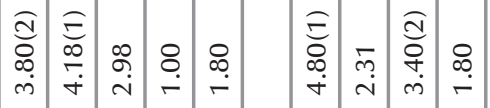

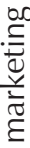

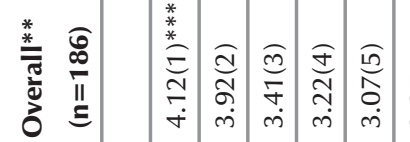

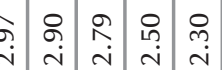

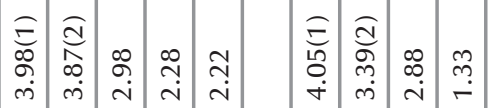

ᄃ

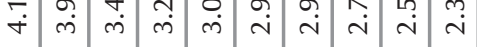

-

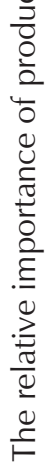

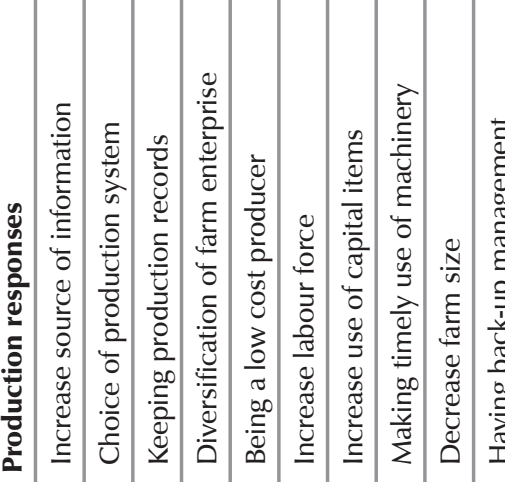

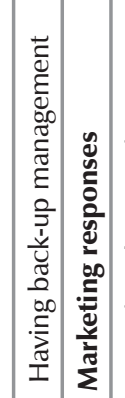

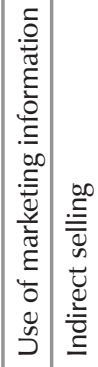
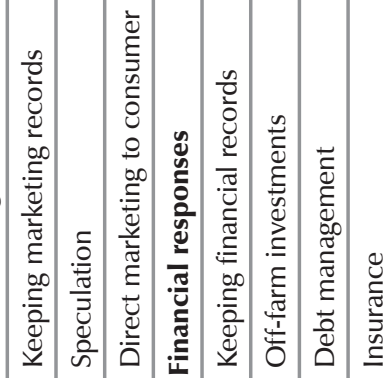
With the exceptions of having back-up management and adoption of agricultural insurance, all risk-management responses were, on average, considered to be important (average ranking of three or greater) by survey respondents for one or more farm types. However, only nine out of 19 risk responses received mean rankings of greater than three across all survey respondents. On average, horticulture farmers ranked a greater number of risk management responses as being important (16 out of 19), and poultry farmers the fewest (7 out of 19). This finding reflects that due to differences in marketing arrangements across different products, different sets of risk responses are applicable to different farm types. Low rankings may indicate that particular risk responses are potentially important, but not yet available. For example, Mohammed (2004) determined that livestock insurance may become an important risk-management strategy for Eritrean dairy farmers if agricultural insurance markets are developed in Eritrea.

On average, the highest ranked production, marketing and financial risk responses entail the use of information from internal and external sources. The relative importance of information in risk-management strategies by small-scale commercial Eritrean farmers may be high because opportunities for market-related risk responses (e.g. agricultural insurance and futures markets) are undeveloped in Eritrea. The emphasis of poultry and horticulture farmers on increasing sources of information was on the technical aspects of production, whereas field crop farmers focused on information about weather forecasts and availability of new seed varieties.

Besides information orientated productionrisk responses, choice of production system (3.92), diversification of farm enterprises (3.22) and being a low-cost producer (3.07) were, on average, ranked three or greater by the survey respondents. This result is similar to those of a series of similar studies of large-scale commercial farm businesses in South Africa, e.g. Swanepoel and Ortmann (1993), Bullock et al. (1994) and Woodburn et al. (1995). Diversification was, on average, rated as an important productionrisk response by all farmers, except those from
Ma'akel. Reasons for this may include that the relatively small farms in this zoba are not conducive to enterprise diversification, as well as that diversification on Eritrean poultry farms (a common farm type in Ma'akel) is uncommon because many of these poultry farms are government-subsidised projects that specialise in production of layers. Few poultry farmers diversify to produce both broilers and layers because the nature of production and management required for these systems are considerably different.

The choice of production systems used by field crop farmers includes selection of appropriate varieties of crops and timing of seeding. Discussions with extension agents and farmers indicate that farmers grow high-yield crop types (sesame and sorghum) when they anticipate a good rainy season, otherwise they prefer low-yielding or fast-growing crops to resist drought.

On average, the highest ranked noninformation orientated marketing-risk response by the sample of farmers was the choice between direct marketing to consumers and indirect selling, which includes selling to wholesalers, grain board and processing plants. On average, poultry, dairy and crop farmers all rated indirect selling highly $(>4.20)$ and rated direct marketing as not important $(<2.60)$. Horticulture farmers, however, rated direct marketing highly (3.60) and indirect marketing as being less important (2.80). Many of the horticulture farmers surveyed operate retail and/or wholesale businesses. Speculation was rated as an important marketing response to risk by horticulture and crop farmers, but not by poultry and dairy farmers.

Besides keeping financial records, the only financial risk response to be ranked, on average, as being important (mean $>3$ ) is holding offfarm investments (e.g. investments in truck, bus, hotel and shop businesses), which re-emphasises the importance of diversification in Eritrean farmers' risk-management strategies. Debt management is considered to be an important financial risk response by horticulture and poultry farmers, but less important by dairy and crop farmers. Relatively low mean rankings for debt management and insurance probably 
reflect that Eritrean small-scale commercial farmers have relatively poor access to credit, and that agricultural insurance markets in Eritrea are currently poorly developed, although limited livestock insurance products are available to dairy farmers (Mohammed, 2004).

\subsection{Factor analysis of managerial responses to risk}

Analysis of means and standard deviations in Table 1 show only the distribution of farmers' managerial responses to risk. Factor analysis (FA) may be used to identify any interrelationships among farmers' perceptions of various management tools to risks and therefore provides more insight into their risk management strategies. It is noted, however, that some correlation between farmers' managerial responses to risk may be coincidental and not necessarily related. If orthogonal factors are elicited, this use of FA may be described as an analysis of the dimensionality of management strategy to risks (Woodburn et al., 1995). In this study, the FAs were conducted through application of varimax rotations to provisional principal components. Varimax rotation attempts to minimise the number of variables that have high loadings on a factor (Norŭsis, 1994), in order to elicit orthogonal factors that are more easily interpreted (Manly, 1994).

FA of pooled data for all four farm types revealed that the primary sources of heterogeneity among farmers' perceptions of risk responses are related to farm type. Considering that Table 1 reveals marked differences in the value and order of mean farmers' rankings of risk responses across farm types, this finding was expected. In order to focus on more meaningful relationships between riskmanagement responses, FA was conducted for each farm type separately. Risk-management tools for which farmers did not vary in their responses were excluded from these respective analyses. Results of these analyses are presented in Tables 2 to 5. Mean factor scores were computed for each zoba. In addition, correlation matrices were computed for elicited factors and a selection of socioeconomic variables, including farm size, education, leverage and farming experience, to examine if grouping of managerial responses in elicited factors can be explained better by considering these variables than by only considering differences between geographic regions.

To assess the significance of the intercorrelation matrix as a whole, Bartlett's test of sphericity was applied for each of the four analyses. Chisquared values reported in Tables 2 to 5 are all significantly different from zero, indicating that one or more of the correlations in each of the intercorrelation matrices are statistically significant.

In the FA of poultry farmers' perceptions of risk responses (Table 2), mean factor scores for the first factor vary widely between the zobatat, and the estimated correlation coefficient (r) between the first factor and farm size is 0.32 , suggesting that an important source of variation in poultry farmers' risk- management strategies is attributable to regional differences in labour availability as well as economies of farm size. Labour is relatively more abundant in Gash-Barka, consequently poultry farmers in this zoba are more able to employ additional labourers as a risk response than farmers in Ma'akel and Debub. An alternative production risk management strategy is to have back-up management, make timely use of machinery and aiming to be a low cost producer. This strategy is more feasible on larger farms as fixed costs of management and machinery ownership can be spread over a greater volume of production.

The second-largest source of variation in sample poultry farmers' ranking of risk responses is the importance they attached to marketing options in their risk-management strategies. Farmers with relatively high scores for factor 2 consider indirect selling to be relatively more important, and direct marketing to consumers to be relatively less important, compared to other poultry farmers in the sample. Factor scores for each zoba show that poultry farmers from Ma'akel are relatively more likely to favour indirect marketing over direct marketing to consumers than other poultry farmers. Ma'akel is characterised by relatively good infrastructure, consequently dealers can operate more easily in this zoba. 
Table 2

Rotated factor loadings* and factor scores of managerial responses to risk for sample commercial poultry farmers in the three zobatat of Eritrea, 2002/03 $(n=40)$.

\begin{tabular}{|c|c|c|c|c|c|c|c|}
\hline & \multicolumn{6}{|c|}{ Factor } \\
\hline & & 1 & 2 & 3 & 4 & 5 & 6 \\
\hline \multicolumn{2}{|l|}{ Eigenvalues } & 4.66 & 2.68 & 1.68 & 1.59 & 1.38 & 1.33 \\
\hline \multicolumn{2}{|c|}{ Percentage of variance explained } & 20.35 & 12.53 & 11.03 & 9.61 & 7.30 & 6.47 \\
\hline \multicolumn{8}{|c|}{ Bartlett's test of sphericity: Chi-Square $=171.305$ Sig. 001} \\
\hline Managerial responses & Communalities** & & & & & & \\
\hline $\begin{array}{l}\text { Having back-up } \\
\text { management }\end{array}$ & 0.784 & 0.835 & & & & & \\
\hline $\begin{array}{l}\text { Making timely use of } \\
\text { machinery }\end{array}$ & 0.537 & 0.671 & & & & & \\
\hline Being a low cost producer & 0.817 & 0.660 & & & & & 0.504 \\
\hline Increase labour force & 0.647 & -0.584 & & & & & \\
\hline Indirect selling & 0.852 & & 0.875 & & & & \\
\hline $\begin{array}{l}\text { Direct marketing to } \\
\text { consumer }\end{array}$ & 0.739 & & -0.807 & & & & \\
\hline $\begin{array}{l}\text { Choice of production } \\
\text { system }\end{array}$ & 0.630 & & 0.579 & & & & \\
\hline $\begin{array}{l}\text { Diversification of farm } \\
\text { enterprise }\end{array}$ & 0.652 & & & 0.719 & & & \\
\hline Off-farm investment & 0.587 & & & -0.717 & & & \\
\hline Debt management & 0.732 & & & 0.715 & & & \\
\hline Keeping production records & 0.875 & & & & 0.921 & & \\
\hline Keeping financial records & 0.834 & & & & 0.857 & & \\
\hline $\begin{array}{l}\text { Increase source of } \\
\text { information }\end{array}$ & 0.760 & & & & 0.639 & & \\
\hline Keeping marketing records & 0.831 & & & & & 0.847 & \\
\hline $\begin{array}{l}\text { Use of marketing } \\
\text { information }\end{array}$ & 0.710 & & & & & 0.567 & \\
\hline Increase use of capital items & 0.770 & & & & & & 0.778 \\
\hline Zoba & & & & Facto & score & & \\
\hline Ma'akel & & 1.88 & 0.84 & -0.27 & 0.13 & -0.15 & 0.02 \\
\hline Debub & & 0.05 & -0.33 & -0.60 & 0.25 & 0.18 & 0.42 \\
\hline Gash-Barka & & -2.87 & -0.44 & 1.44 & -0.25 & -0.19 & -0.93 \\
\hline
\end{tabular}

* Only factor loadings with an absolute value greater than 0.4 are shown.

** Part of the variable's variance that is related to the common factors. 
Poultry farmers also vary significantly in their choices of financial risk responses. Factor 3 identifies that poultry farmers regard on-farm diversification and off-farm diversification as substitute risk responses. Farmers who have a relative preference for off-farm diversification, compared to other poultry farmers, tend to have a relatively low regard for debt management as a risk response. Factor 3 of this analysis is positively correlated with farm size $(r=0.22)$, suggesting that poultry farmers with larger farms tend to attach greater importance to onfarm diversification, whereas those who favour off-farm diversification tend to have higher leverage.

Factors 4 and 5 indicate that despite the high mean ratings attached to the importance of internal and external sources of information in risk management by poultry farmers in the sample, these farmers do differ in the importance they attach to these risk responses in their risk management strategies. Key findings indicated in these factors are that while farmers' ratings of keeping production and financial records are positively correlated, they are not necessarily related to their ratings of keeping marketing records or using marketing information. Factor
4 is positively correlated with education $(\mathrm{r}=$ 0.42), reflecting that better educated farmers tend to rate keeping production and financial records relatively highly as part of their riskmanagement strategies. This result supports the supposition that education improves farmers' abilities to source and analyse internal and external information in decision-making.

In the FA of dairy farmers' rankings of the risk responses (Table 3), three factors account for 50 per cent of the variation in their responses. The first factor primarily identifies variation in the importance sample dairy farmers attached to production-risk responses. There is a positive correlation between the importance dairy farmers attach to diversification and increasing their labour forces as risk responses, but negative correlation between the importance attached to these risk responses and the importance farmers attached to having back-up management and increased use of capital items. Mean factor scores for the zobatat differ widely and the factor is positively correlated with farm size ( $\mathrm{r}=$ 0.40 ), once again suggesting that as for Eritrean poultry farms, availability of farm labour and farm size are important determinants of farmers' risk-management strategies.

Table 3

Rotated factor loadings* and factor scores of managerial responses to risk for sample commercial dairy farmers in the three zobatat of Eritrea, 2002/03 $(n=74)$.

\begin{tabular}{|c|c|c|c|c|c|c|c|}
\hline & \multicolumn{6}{|c|}{ Factor } \\
\hline & & 1 & 2 & 3 & 4 & 5 & 6 \\
\hline Eigenvalues & & 3.66 & 3.01 & 2.32 & 1.39 & 1.31 & 1.04 \\
\hline $\begin{array}{l}\text { Percentage of variance } \\
\text { explained }\end{array}$ & & 20.37 & 16.72 & 12.91 & 7.27 & 7.26 & 5.78 \\
\hline \multicolumn{8}{|c|}{ Bartlett's test of sphericity: Chi-Square $=560.810$ Sig. 000} \\
\hline Managerial responses & Communalities** & & & & & & \\
\hline Increase labour force & 0.708 & 0.827 & & & & & \\
\hline Increase use of capital items & 0.657 & -0.773 & & & & & \\
\hline Diversification of farm enterprise & 0.888 & 0.764 & & & 0.485 & & \\
\hline Speculation & 0.605 & 0.612 & & & & & \\
\hline Having back-up management & 0.525 & -0.518 & & & & & \\
\hline
\end{tabular}




\begin{tabular}{|c|c|c|c|c|c|c|c|}
\hline Insurance & 0.852 & & 0.893 & & & & \\
\hline Off-farm investment & 0.803 & & -0.839 & & & & \\
\hline Debt management & 0.575 & & 0.795 & & & & \\
\hline Keeping financial records & 0.570 & & 0.540 & & & & 0.469 \\
\hline Direct marketing to consumer & 0.831 & & & 0.887 & & & \\
\hline Indirect selling & 0.753 & & & -0.733 & & & \\
\hline Choice of production system & 0.670 & & & & 0.715 & & \\
\hline Increase source of information & 0.633 & & & & 0.722 & & \\
\hline Use of marketing information & 0.531 & & & & -0.550 & & \\
\hline Making timely use of machinery & 0.679 & & & & & 0.805 & \\
\hline Being a low cost producer & 0.730 & & & & & 0.619 & \\
\hline Keeping production records & 0.774 & & & & & & 0.843 \\
\hline Keeping marketing records & 0.769 & & & & & & 0.842 \\
\hline Zoba & & \multicolumn{6}{|c|}{ Factor scores } \\
\hline Ma'akel & & -4.28 & 1.25 & -0.26 & -2.25 & -0.25 & 0.38 \\
\hline Debub & & 2.08 & -0.39 & -0.70 & 2.50 & 0.24 & 0.26 \\
\hline Gash-Barka & & 0.67 & -1.13 & 3.50 & 0.88 & -0.46 & -0.27 \\
\hline
\end{tabular}

* Only factor loadings with an absolute value greater than 0.4 are shown.

** Part of the variable's variance that is related to the common factors.

The second factor in Table 3 highlights variations in the importance sample dairy farmers attach to various financial risk responses. Its structure is similar to that of factor 3 in Table 2; however, it also includes a high factor loading for insurance, a risk response that is only available to livestock farmers in Eritrea. A positive correlation between this factor and respondents' education $(\mathrm{r}=0.48)$ indicates that better educated dairy farmers attach relatively high importance to use of insurance and debt management but relatively low importance to off-farm diversification in their risk-management strategies. The third factor highlights variation dairy farmers attach to marketing options as risk responses. Factor scores indicate that dairy farmers in GashBarka attach a relatively high importance to direct marketing to consumers compared to those from Ma'akel and Debub. Gash-Barka is characterised by poor infrastructure relative to Ma'akel and Debub, which may account for this finding.
Table 4 presents results of the FA of horticulture farmers' rankings of risk responses. The percentage of variation explained by factor 1 is high compared to the other factors elicited in this analysis. It reflects that the importance sample horticulture farmers attach to marketing options as risk responses accounts for a large proportion of variation in their risk-management strategies. Factor scores indicate that horticulture farmers from Gash-Barka attach a relatively high importance to direct marketing to consumers compared to farmers from Ma'akel and Debub. The poor infrastructure of Gash-Barka relative to Ma'akel and Debub may account for the relative absence of marketing agents in this zoba. The second factor primarily identifies that sample horticulture farmers differ in their opinions regarding increasing capital intensity as a risk-management response. Not surprisingly, this factor was found to be positively correlated with the business leverage ratio $(r=0.44)$. 


\section{Table 4}

Rotated factor loadings* and factor scores of managerial responses to risk for sample commercial horticulture farmers in the three zobatat of Eritrea, 2002/03 $(n=31)$.

\begin{tabular}{|l|c|c|c|c|c|c|c|}
\hline \multirow{2}{*}{} & \multicolumn{7}{|c|}{ Factor } \\
\cline { 2 - 9 } & 1 & 2 & 3 & 4 & 5 & 6 & 7 \\
\hline Eigenvalues & 4.48 & 2.88 & 1.68 & 1.46 & 1.33 & 1.19 & 1.13 \\
\hline Percentage of variance explained & 24.90 & 10.42 & 9.33 & 8.08 & 7.40 & 6.58 & 6.27 \\
\hline
\end{tabular}

Bartlett's test of sphericity: Chi-Square $=189.678$ Sig. 0.023

\begin{tabular}{|l|c|c|c|c|c|l|l|l|}
\hline Managerial responses & Communalities* & \multicolumn{2}{|l}{} & & & & \\
\hline $\begin{array}{l}\text { Direct marketing to } \\
\text { consumer }\end{array}$ & 0.778 & $\mathbf{0 . 8 5 1}$ & & & & & & \\
\hline Speculation & 0.805 & $\mathbf{0 . 8 6 2}$ & & & & & & \\
\hline Indirect selling & 0.720 & $\mathbf{- 0 . 7 5 3}$ & & & & & & \\
\hline Use of marketing information & 0.729 & $\mathbf{0 . 5 6 0}$ & & & & & & \\
\hline Increase use of capital items & 0.831 & & $\mathbf{0 . 8 3 2}$ & & & & & \\
\hline $\begin{array}{l}\text { Increase source of } \\
\text { information }\end{array}$ & 0.622 & & $\mathbf{0 . 5 6 5}$ & $\mathbf{0 . 4 4 4}$ & & & & \\
\hline Being a low cost producer & 0.755 & & $\mathbf{0 . 5 5 6}$ & & & & & \\
\hline Keeping marketing records & 0.917 & & & $\mathbf{0 . 8 5 6}$ & & & & \\
\hline Keeping production records & 0.800 & & & $\mathbf{0 . 8 2 0}$ & & & & \\
\hline Decrease farm size & 0.585 & & & $\mathbf{0 . 4 6 7}$ & & & & \\
\hline Debt management & 0.657 & & & & $\mathbf{0 . 7 8 0}$ & & & \\
\hline Increase labour force & 0.684 & & & & $\mathbf{0 . 6 8 6}$ & & & \\
\hline Off-farm investment & 0.689 & & & & $\mathbf{0 . 6 1 7}$ & & & \\
\hline $\begin{array}{l}\text { Diversification of farm } \\
\text { enterprise }\end{array}$ & 0.768 & & & & & $\mathbf{0 . 8 5 4}$ & $\mathbf{0 . 4 0 3}$ & \\
\hline Choice of production system & 0.614 & & & & & $\mathbf{0 . 7 3 0}$ & & \\
\hline $\begin{array}{l}\text { Making timely use of } \\
\text { machinery }\end{array}$ & 0.799 & & & & & & $\mathbf{0 . 8 7 1}$ & \\
\hline Having back-up management & 0.785 & & & & & & & $\mathbf{0 . 6 4 5}$ \\
\hline Keeping financial records & 0.601 & & & $\mathbf{0 . 4 3 1}$ & & & & $\mathbf{0 . 4 3 2}$ \\
\hline Zoba & & & & & & & & \\
\hline Ma'akel & & & & & & & & \\
\hline Debub & & & & & & & & \\
\hline Gash-Barka & & & & & & & & \\
\hline
\end{tabular}

* Only factor loadings with an absolute value greater than 0.4 are shown.

** Part of the variable's variance that is related to the common factors. 
Results of the FA of sample crop farmers' rankings of risk responses are presented in Table 5. The first two factors of this analysis each explain a large proportion of variation in the data compared to the other factors. Factor 1 identifies a dimension of risk management that is primarily a financial risk response, i.e. to partially disinvest from agriculture and invest in off-farm businesses. A correlation analysis indicated that this risk response is more likely to be considered important as a risk response by farmers with relatively large farms $(\mathrm{r}=0.32)$. Making timely use of machinery is complementary to this risk response; however, the risk response of being a low-cost producer is not. The second factor identifies that becoming more labour intensive and more capital intensive are substitute production risk responses, and that for Eritrean crop farms, relatively more labour-intensive farming is a complementary risk response to on-farm diversification. Factor scores show that relative to sample crop farmers in Ma'akel and Debub, sample crop farmers from Gash-Barka, where labour is relatively abundant, are more likely to implement on-farm diversification and to increase their labour force as part of their risk-management strategies.

Table 5

Rotated factor loadings* and factor scores of managerial responses to risk for sample commercial crop farmers in the three zobatat of Eritrea, 2002/03 $(n=41)$.

\begin{tabular}{|c|c|c|c|c|c|c|c|}
\hline & & \multicolumn{6}{|c|}{ Factor } \\
\hline & & 1 & 2 & 3 & 4 & 5 & 6 \\
\hline \multicolumn{2}{|l|}{ Eigenvalues } & 4.95 & 3.26 & 1.77 & 1.22 & 1.11 & 1.03 \\
\hline \multicolumn{2}{|l|}{ Percentage of variance explained } & 27.51 & 18.10 & 9.85 & 6.79 & 6.16 & 5.72 \\
\hline \multicolumn{8}{|c|}{ Bartlett's test of sphericity: Chi-Square $=367.286$ Sig. 000} \\
\hline Managerial responses & Communalities** & & & & & & \\
\hline Decrease farm size & 0.819 & 0.866 & & & & & \\
\hline Off-farm investment & 0.654 & 0.704 & & & & 0.564 & \\
\hline Making timely use of machinery & 0.634 & 0.584 & & & & & \\
\hline Being a low cost producer & 0.861 & -0.539 & & & & & \\
\hline Increase labour force & 0.681 & & 0.855 & & & & \\
\hline Increase use of capital items & 0.812 & & -0.735 & & & & \\
\hline $\begin{array}{l}\text { Diversification of farm } \\
\text { enterprise }\end{array}$ & 0.638 & & 0.668 & & 0.423 & & \\
\hline Indirect selling & 0.802 & & & 0.890 & & & \\
\hline Direct marketing to consumer & 0.849 & & & -0.868 & & & \\
\hline Speculation & 0.765 & & & -0.566 & & & \\
\hline Use of marketing information & 0.580 & & & -0.538 & & & \\
\hline Increase source of information & 0.517 & & & & 0.875 & & \\
\hline Choice of production system & 0.772 & & & & 0.820 & & \\
\hline Having back-up management & 0.634 & & & & & 0.711 & \\
\hline Debt management & 0.810 & & & & & -0.526 & \\
\hline
\end{tabular}




\begin{tabular}{|c|c|c|c|c|c|c|c|}
\hline Keeping production records & 0.808 & & & & & & 0.739 \\
\hline Keeping marketing records & 0.771 & & & & & & 0.512 \\
\hline Keeping financial records & 0.865 & & & & & -0.454 & 0.466 \\
\hline Zoba & & \multicolumn{6}{|c|}{ Factor scores } \\
\hline Ma'akel & & -1.62 & -0.84 & -0.63 & -1.51 & -1.69 & 0.05 \\
\hline Debub & & -1.67 & -1.61 & 0.35 & 0.40 & -0.78 & 0.37 \\
\hline Gash-Barka & & 0.54 & 1.99 & 3.13 & 4.46 & 0.31 & -0.10 \\
\hline
\end{tabular}

Marked differences between the four sets of elicited factors in Tables 2 to 5 suggest that farmers' risk-management strategies are likely to differ according to farm type. For example, insurance only received a high loading in Table 3 because this risk response is currently only available to livestock farmers in Eritrea. Likewise, variation in farmers' perceptions of marketing options as risk responses accounted for less than 10 per cent of variation in the data for sample crop farmers, but almost 25 per cent of variation in the data for sample horticulture farmers. This reflects that the marketing of crops, dairy and eggs is more regulated than the marketing of horticultural products in Eritrea. Finally, it is evident that while some risk responses are complementary for some farm types, they may be substitutes or unrelated for other farm types. For example, loadings for being a low-cost producer and making timely use of machinery both carry positive loadings in factor 1 of Table 2 and factor 5 of Table 3 , but different signs in factor 1 of Table 5 . This reflects differences in the nature of production of poultry and dairy production compared to crop production.

However, there are also striking similarities between the four factor analyses, indicating variation in farmers' rankings of risk responses not related to farm type. In all four analyses, each elicited factor tends to be dominated by risk responses from only one of four categories of risk responses: production responses, marketing responses, financial responses, and use of information. In many instances, most notably for marketing options, the structure of the corresponding factors in the respective factor analyses is very similar. Factors that may account for this additional variation in sample farmers' perceptions of risk responses include (a) geographical location; (b) farmer characteristics, such as education and risk preference; and (c) farm business characteristics, such as farm size and financial leverage.

In the previous section, geographical location was identified as a possible reason for farmers' relative preferences for direct versus indirect marketing. Specifically, it was noted that relatively poor infrastructure and the relatively more rural nature of Gash-Barka may partially account for the relative absence of marketing agents in this zoba, and hence the relative preference of farmers from Gash-Barka for direct marketing compared to farmers from Ma'akel and Debub. Likewise, the relative abundance of labour in Gash-Barka compared to the other study areas may partially account for farmers from this zoba tending to show a preference for labour-intensive farming over capital-intensive farming. Finally, the extent of various risks differs between zobatat, which may also give rise to geographically related variation in farmers' risk-management strategies. Simple correlation analyses were used to identify possible relationships between elicited factors and farmer and farm business characteristics. Results suggest that there are positive relationships between use of information and education, and between farm size and on-farm diversification. 
5

\section{Conclusions and policy implications}

An analysis of sample farmers' mean rankings of risk responses identified the use of internal and external sources of information to be the most highly rated risk response. Considering the positive relationship identified between farmers' education and perceptions of internal and external sources of information as risk responses, programmes that educate and train farmers in record keeping and analysis and in sourcing useful information, are expected to contribute towards improving risk management on small-scale commercial farms in Eritrea. Private consultants, financiers and insurers could also play an essential role in providing relevant information and advice.

On-farm and off-farm diversification are also highly important risk responses for Eritrean farmers. Government subsidised agricultural projects should not restrict farmers from practising enterprise diversification. The high relative importance of off-farm diversification as a risk response in Gash-Barka reflects the relatively high levels of production and socioeconomic risks that characterise this region. Increased political stability is important to encourage farmers in this zoba to invest relatively more in farming.

It is contended that low mean rankings of some risk responses do not necessarily imply that the risk response is not potentially important to farmers, but rather that some of these risk responses are not easily available to farmers. Policies that, for example, improve farmers' access to agricultural credit, develop markets for agricultural insurance, and deregulate marketing channels, may lead to an increase in the importance of debt management, adoption of insurance and direct marketing to consumers in Eritrean farmers' risk management strategies.

While some risk responses are important on all types of farm, the relative importance of others varies considerably among enterprises. Findings partially ascribe observed heterogeneity in sample farmers' perceptions of the risk responses to farm type, geographical location, farmer and farm characteristics, regulation of markets for some farm products, and the existence of enterprise specific risk responses (e.g. livestock insurance). Recommendations that arise from these findings include that the Eritrean Ministry of Agriculture should investigate the possibility of providing additional agricultural insurance products to commercial farmers. Secondly, in order to improve marketing risk management on commercial farms the Eritrean Ministry of Agriculture should not regulate the marketing of products, but rather develop infrastructure and institutions that will lower transaction costs in product markets. Research is required to determine whether futures markets are likely to be viable in Eritrea.

\section{Endnote}

1 The authors thank two anonymous referees for their comments on an earlier draft of the paper. The usual disclaimers apply.

\section{References}

1 ARROW, K.J. (1971) Essays in the Theory of Risk Bearing, Markham Publishing Company: Chicago.

2 BARRY, P.J., ELLINGER, P.N., HOPKIN, J.A. \& BAKER, C.B. (2000) Financial Management in Agriculture (6 ${ }^{\text {th }}$ ed.) Interstate Publishers Inc: Danville: Illinois.

3 BEKURETSION, H. (2002) "The coexistence of commercial and traditional farming in Eritrea", Paper presented at the Ministry of Agriculture Annual Conference, Asmara, Eritrea.

4 BINSWANGER, H.P. (1980) "Attitudes towards risk: Experimental measurement in rural India”, American Journal of Agricultural Economics, 62: 395-407.

5 BOEHLJE, M.D. \& TREDE, L.D. (1977) "Risk management in agriculture", Journal of the American Society of Farm Managers and Rural Appraisers, 41: 20-27.

6 BULLOCK, W.I.; ORTMANN, G.F. \& LEVIN, J.B. (1994) "Risk sources and managerial responses to risk in vegetable farming: Evidence from large- and small-scale commercial vegetable farmers in KwaZulu-Natal”, Agrekon, 33(3): 103-112.

7 CIA (Central Intelligence Agency) (2005) World Fact Book, http://www.cia.gov/cia/publications/ factbook/index.html. (Accessed 24 February 2005).

8 DEBERTIN, L.D. (1986) Agricultural Production Economics, Macmillan Publishing Company: New York. 
9 EIDMAN, V.T. (1990) "Quantifying and managing risk in agriculture”, Agrekon, 29: 11-23.

10 FLEISHER, B. (1990) Agricultural Risk Management, Lynne Rienner Publishers: Boulder and London.

11 GHEBREYOHANES, F. (2000) "The interface between local and macro-perspectives: An analysis of the impact of the SG 2000 Program in Eritrea", Unpublished MSc thesis, Department of Economics and Marketing, Wageningen University, The Netherlands.

12 HARDAKER, J.B.; HUIRNE, R.B.M. \& ANDERSON, J.R. (1997) Coping with Risk in Agriculture, CAB International: Wallingford, Oxon, UK.

13 HARWOOD, J., HEIFNER, R.; COBLE, K.; PERRY, J. \& SOMWARU, A. (1999) "Managing risk in farming: Concepts, research, and analysis", Agricultural Economics Report No. 774, Economic Research Service, USDA.

14 HAZELL, P.B.R. (1982) "Application of risk preference estimates in firm-household and agricultural sector models", American Journal of Agricultural Economics, 64: 384-390.

15 HELD, L.J. (1990) "Evaluating risk in wholefarm planning: Chance and amount of loss versus income variability", Journal of the American Society of Farm Managers and Rural Appraisers, 54: 54-57.

16 MANLY, B.F.J. (1994) Multivariate Statistical Methods, Chapman and Hall: London.

17 MOHAMMED, M.A. (2004) "Perceptions and management of risk by commercial farmers in Eritrea", Unpublished MScAgric thesis, School of Agricultural Sciences and Agribusiness, University of KwaZulu-Natal, Pietermaritzburg.
18 MOSCARDI, E. \& DE JANVRY, A. (1977) "Attitudes toward risk among peasants: An econometric approach", American Journal of Agricultural Economics, 59: 710-716.

19 NORŬSIS, M.J. (1994) SPSS Professional Statistics 6.1, SPSS Inc: Chicago.

20 ORTMANN, G.F., PATRICK, G.F., MUSSER, W.N. \& DOSTER, D.H. (1992) "Sources and management of risk: Evidence from leading Cornbelt farmers in the USA", Agrekon, 31: 216221.

21 PATRICK, G.F.; MUSSER, W.N. \& ORTMANN, G.F. (1993) "Risk responses of large-scale Cornbelt Farmers", Proceedings of a Seminar sponsored by Southern Regional Project S-232, Department of Resource Economics and Policy, University of Maine, Orono, Maine, June.

22 PRATT, J.W. (1964) "Risk aversion in the small and in the large", Econometrica, 32: 122-136.

23 SONKA, S.T. \& PATRICK, G.F. (1984) "Risk management and decision making in agricultural firms", In: Barry, P.J. (ed.) Risk Management in Agriculture, Iowa State Press: Iowa: 95-115.

24 SWANEPOEL, V. \& ORTMANN, G.F. (1993) "Sources and management of risk in extensive livestock farming in the North-Western Transvaal Bushveld", Agrekon, 32: 196-200.

25 WOODBURN, M.R.; ORTMANN, G.F. \& LEVIN, J.B. (1995) "Sources and management of risk: Evidence from commercial farmers in KwaZulu-Natal", South African Journal of Economic and Management Sciences, 17: 46-63.

26 YOUNG, D.L. (1979) "Risk preferences of agricultural producers: Their use in extension and research", American Journal of Agricultural Economics, 61: 1063-1069. 


\section{Appendix A}

\section{Table A1}

Sample proportions of Eritrean study $(n=186)$

\begin{tabular}{|c|c|c|c|c|c|c|c|c|c|c|c|c|}
\hline \multirow[t]{3}{*}{ Enterprises } & \multicolumn{9}{|c|}{ Zoba } & \multirow{2}{*}{\multicolumn{3}{|c|}{ Total }} \\
\hline & \multicolumn{3}{|c|}{ Ma'akel } & \multicolumn{3}{|c|}{ Debub } & \multicolumn{3}{|c|}{ Gash-Barka } & & & \\
\hline & $\mathbf{N}^{*}$ & $\mathbf{n}^{* *}$ & $\%$ & $\mathbf{N}$ & $\mathbf{n}$ & $\%$ & $\mathbf{N}$ & $\mathbf{n}$ & $\%$ & $\mathbf{N}$ & $\mathbf{n}$ & $\%$ \\
\hline Poultry & 180 & 16 & 8.88 & 210 & 22 & 10.48 & 12 & 2 & 16.7 & 402 & 40 & 9.95 \\
\hline Dairy & 300 & 23 & 7.66 & 320 & 40 & 12.5 & 62 & 11 & 17.7 & 682 & 74 & 10.9 \\
\hline Horticulture & 26 & 2 & 7.69 & 58 & 5 & 8.62 & 305 & 24 & 7.87 & 389 & 31 & 7.97 \\
\hline Crop & 12 & 1 & 8.33 & 60 & 5 & 8.33 & 420 & 35 & 8.33 & 492 & 41 & 8.33 \\
\hline Total & 518 & 42 & 8.10 & 648 & 72 & 11.11 & 799 & 72 & 9.01 & 1965 & 186 & 9.47 \\
\hline
\end{tabular}

* Represents the number of the total population

** Represents the number of farmers in the sample. 